\title{
Prostate Embryonal Rhabdomyosarcoma
}

National Cancer Institute

\section{Source}

National Cancer Institute. Prostate Embryonal Rhabdomyosarcoma. NCI Thesaurus.

Code C5525.

A malignant mesenchymal neoplasm of the prostate. It is characterized by the presence of skeletal muscle exhibiting embryonic features. 